\title{
Skeletal muscle strength and endurance in patients with mild COPD and the effects of weight training
}

\author{
C.J. Clark, L.M. Cochrane, E. Mackay, B. Paton
}

\begin{abstract}
Skeletal muscle strength and endurance in patients with mild COPD and the effects of weight training. C.J. Clark, L.M. Cochrane, E. Mackay, B. Paton. (C)ERS Journals Ltd 1999.

ABSTRACT: This study poses two questions: 1) is there an abnormality in isokinetic skeletal muscle strength and endurance in mild chronic obstructive pulmonary disease (COPD)? and 2) what is the effect of a randomized, controlled, 12 week hospital outpatient weight training programme in terms of skeletal muscle function and exercise tolerance?

Upper and lower limb isokinetic maximum and sustained muscle function were compared in 43 COPD patients (age $49 \pm 11$ yrs), mean forced expiratory volume in one second (FEV1) $77 \pm 23 \%$ pred and 52 healthy, sedentary subjects (age 51 (10) yrs), mean FEV1 $109 \pm 16 \%$ pred. The 43 COPD patients were randomly allocated into training $(n=26)$ and control $(n=17)$ groups. Isokinetic and isotonic muscle function, whole body endurance, maximal exercise capacity and lung function were measured.

The COPD patients had reduced isokinetic muscle function (with the exception of sustained upper limb strength) as compared with healthy sedentary subjects. Muscle function improved after weight training in the COPD patients. Whole body endurance during treadmill walking also improved with no change in maximal oxygen consumption.

A deficit in skeletal muscle function can be identified in patients with mild chronic obstructive pulmonary disease which cannot be explained by factors such as hypoxaemia and malnutrition. Intervention with weight training is effective in countering this deficit which the authors conclude is probably due to muscle deconditioning. Eur Respir J 2000; 15: 92-97.
\end{abstract}

\begin{abstract}
Dept of Respiratory Medicine, Hairmyres Hospital, East Kilbride, Glasgow, UK, and Centre for Exercise Science and Medicine University of Glasgow, UK.
\end{abstract}

Correspondence: C.J. Clark

Hairmyres Hospital

East Kilbride

Glasgow G75 8RG

Scotland

Fax: 441355260852

Keywords: Chronic obstructive

pulmonary disease

pulmonary rehabilitation

skeletal muscle

weight training

Received: November 251998

Accepted after revision August 221999
It has recently been shown that peripheral muscle weakness contributes to exercise limitation in chronic obstructive pulmonary disease (COPD) $[1,2]$. Functional and morphological skeletal muscle abnormalities [3-6] have been reported in patients with COPD and are thought to relate to a variety of factors such as hypoxaemia, malnutrition, ageing and disuse causing deconditioning. If the latter is identifiable at a relatively early stage of the illness, when other secondary complications are absent there may be a therapeutic window for intervention to reduce the disability associated with COPD.

This study was designed in two parts: 1) to examine the maximum and the sustained (endurance) strength of peripheral skeletal muscle in mild COPD patients compared with normal, healthy but sedentary subjects using isokinetic measures of muscle strength. This was the preferred choice of testing in order to comprehensively assess skeletal muscle function throughout the normal full range of motion; 2) to examine the effects of a pulmonary rehabilitation programme of skeletal muscle training in improving muscle function and exercise tolerance in this group of patients.

\section{Methods}

\section{Patients and study design}

Forty-three patients (age $49 \pm 11$ yrs; 25 male and 18 female) were recruited from the Hairmyres Hospital, (UK) Chest Clinic. All were suffering from COPD defined by using the compound definition of SNIDER [7], "Chronic obstructive pulmonary disease is defined as a disease state characterized by the presence of chronic-bronchitis and/ or emphysema associated with airflow obstruction; the airflow obstruction may be accompanied by airways hyper-reactivity and may be partially reversible". They had a mean forced expiratory volume in one second (FEV1) of $77 \pm 23 \%$ predicted. Patients with severe airflow obstruction complicated by resting or exercise hypoxaemia or hypercapnia, long term oral steroid therapy or age $>65$ yrs, plus any other significant concomitant illness such as unstable ischaemic heart disease or severe osteoarthritis were excluded from the study. Fifty-two, sedentary (as defined by "Physical Activity Scores" [8]) healthy subjects (age $51 \pm 10$ yrs; 27 male and 25 female) with normal lung function (FEV1, 109 $\pm 16 \%$ pred) volunteered to undergo dynamic spirometry and tests of isokinetic muscle strength and endurance.

The 43 COPD patients were randomly allocated into training $(n=26 ; 15$ male and 11 female $)$ or control $(n=17$; 10 male and 7 female) groups, i.e. with a $3: 2$ training versus control ratio. Measurements of peripheral muscle endurance and strength, whole body endurance, maximal exercise capacity (maximal oxygen consumption $\left(V^{\prime} \mathrm{O}_{2}\right.$ max) and lung function were made in both groups before and after the 12 week study period. Patients in the training group attended the hospital twice a week where they performed a warm-up either cycling or treadmill walking. 
This was followed by three sets of 10 repetitions of eight individual weight exercises. The predominant muscle group tested is given in brackets: 1) bench press (triceps); 2) body squat (quadriceps); 3) squat calf (medial and lateral gastrocnemius; soleus); 4) latissimus (latissimus dorsi); 5) arm curls (biceps); 6) leg press (quadriceps; hamstrings; gluteals); 7) knee flexion (quadriceps); 8) hamstrings. Thereafter all patients cooled down using cycling or treadmill walking.

Each of the eight exercises was set at a load representing $70 \%$ of the subject's maximum. This was maintained until week 6 of the study period when a new $70 \%$ maximum value was determined for that individual. The last 6 weeks of training was undertaken at this new workload. The control group had no exercise intervention and were advised to continue their usual daily activities. After 12 weeks the initial assessments were repeated on both the training and control group.

\section{Measurements}

Peripheral muscle strength. Isotonic muscle strength (with external loading). The series of eight isolated, sequential, isotonic muscle exercises, which were developed on the Multigym and used as the basis of training during the 12 week study period also served as an evaluation. Each patient was maximally tested on each of the eight individual exercises. The one-repetition maximal 1RM test [9] was modified by using repetitions on increasing submaximal weights as the means of a warm-up. Patients progressed through the weights with which they reached a weight that they were no longer able to complete the full range of movement. The maximum weight which could be successfully shifted through the full range of movement was recorded and $70 \%$ of this was used as the patient's training load for the first 6 weeks. The modified 1RM test was repeated at this point to determine a new $70 \%$ maximum value for the last 6 weeks of the programme.

Isokinetic muscle strength tests. The KIN-COM125E (Kinetic-Communicator; Chattecx Corp., Chattanooga Group Inc., Hixson, TN, USA) was used to measure two different aspects of isokinetic strength, i.e. a maximum contraction test, measuring average peak torque, and a sustained (60 s) repeated contraction test, measuring total work (joules), each of which were performed on the right upper and lower limbs in separate tests. (For the upper limb the tricep and posterior deltoid groups were tested and for the lower limb, the quadriceps group.) The lever speed was set at $70^{\circ} \cdot \mathrm{s}^{-1}$ for both tests.

Whole body exercise test. Endurance walk test. This was performed on a treadmill. The total work performed during the endurance walk test was calculated in three stages. The power (watts) at each speed was determined using the following equation:

$$
\begin{aligned}
& \text { Power }(\mathrm{W})=0.536 \times \text { weight }(\mathrm{kg}) \times \\
& 0.625 \times \text { speed }\left(\mathrm{km} \cdot \mathrm{h}^{-1}\right) \times 0.1635
\end{aligned}
$$

The work (joules) performed at each speed was determined using the following equation:

$$
\text { Work }(\mathbf{J})=\operatorname{power}(\mathrm{W}) \times(\mathrm{s})
$$

The total work performed was a summation of the work performed at each speed [10].

Aerobic exercise testing. Progressive incremental exercise using a bicycle ergometer was undertaken by the patients $10 \mathrm{~min}$ after bronchodilator administration. Work increments of between 5-20 W increased at 1 min intervals until exhaustion (System 2900; Sensor Medics, Yorba Linda, CA, USA). Breathlessness was measured using the modified Borg Scale [10].

\section{Statistical analysis}

For the comparison of muscle function between patients with airflow obstruction and normal healthy sedentary subjects, multiple regression analysis was performed on the isokinetic strength variables. This type of analysis takes account of the multifactorial influence on muscle function of age, weight, height and sex, and the two groups were compared after adjustment for these factors $(\mathrm{p}<0.05$ was considered to be statistically significant).

The distribution of data sets were viewed for normality using box plots. If considered to deviate from a normal distribution a nonparametric statistical test was used for group comparisons. Statistical analysis examined changes from baseline in both the training and control groups, i.e. to minimise the effects of "between-subject" variability by looking at only "within-subject" variability using either Student's t-test (parametric) or Wilcoxon test (noparametric). To illustrate the magnitude of the effects of the weight training programme, the same approach is used as in a previous paper [10] where examples of key efficacy variables are given as "before and after" plots with summaries of mean differences and 95\% confidence intervals $(95 \%$ CI) which are presented after the mean difference (x, y). Where a nonparametric test has been used, the median plus the interquartile range is given. For clarity, not all the data has been presented in these plots but where relevant, summary statistics are given for other efficacy variables within the text.

The magnitude of linear association between pairs of continuous variables was evaluated using Pearson's coefficient of correlation.

\section{Results}

Comparison of healthy sedentary subjects and COPD patients

The healthy sedentary subjects and the COPD patients were compared at the outset of the study (table 1). There were no significant differences other than FEV1 $(p<$ 0.001). An example of the results of multiple regression analysis to determine which factors influence isokinetic muscle strength is given in the following equation:

$$
\begin{aligned}
& \mathrm{LC}(\mathrm{SUS})=616-285^{\prime C O O P D}{ }^{\prime \prime}+277 \text { Sex }-8.2 \\
& \text { Age }+12.3 \mathrm{Wt} \quad\left(\mathrm{r}^{2}=0.42, \text { SEE 339 }\right)
\end{aligned}
$$

Where LC = lower limb concentric contraction, $(\mathrm{SUS})=$ repeated contractions sustained for $60 \mathrm{~s}$ (joules), "COPD" $=1$ for patients with COPD and 0 for healthy sedentary 
Table 1. - Key characteristics of healthy subjects and chronic obstructive pulmonary disease (COPD) patients at outset of study

\begin{tabular}{lcc}
\hline & $\begin{array}{c}\text { Healthy subjects } \\
\mathrm{n}=52\end{array}$ & $\begin{array}{c}\text { COPD patients } \\
\mathrm{n}=43\end{array}$ \\
\hline Age yrs & $51 \pm 10$ & $49 \pm 11$ \\
$\mathrm{Ht} \mathrm{cm}$ & $166 \pm 10$ & $167 \pm 11$ \\
Wt kg & $69 \pm 12$ & $72 \pm 14$ \\
BMI & $25 \pm 3$ & $26 \pm 4$ \\
FEV1 \% pred & $109 \pm 16$ & $77 \pm 23^{*}$ \\
\hline
\end{tabular}

Data are presented as mean \pm SD. *: $\mathrm{p}<0.001$, Student's t-test. Ht: height; Wt: weight; BMI: body mass index $\left(\mathrm{wt} / \mathrm{ht}^{2}\right)$; FEV1: forced expiratory volume in one second as a percentage of the predicted value.

subjects, $\mathrm{Sex}=1$ for males and 0 for females, Age=patient age, $\mathrm{Wt}=$ patient weighth, and $\mathrm{SEE}=$ the standard error of the estimate.

"COPD" accounts for a significant reduction in three of the four measures of isokinetic muscle function, i.e. lower limb maximum and sustained contraction plus upper limb maximum contraction, the exception being the upper limb sustained contraction.

\section{The effects of weight training in COPD patients}

The key characteristics of the 43 COPD patients (training and control groups) are summarized in table 2 . No significant differences were seen. Similarly, there was no significant difference between isotonic or isokinetic muscle strength.

After the study period the training group showed a significant increase in the maximum weight lifted (isotonic) in four of the five lower limb Multigym exercises (e.g. quadriceps strength increased by $7.6 \pm 7.2 \mathrm{~kg}$ in the training group as compared with $0.4 \pm 4.8 \mathrm{~kg}$ in the control group

Table 2. - Key characteristics of the chronic obstructive pulmonary disease (COPD) patients, subdivided into training and control groups, before the 12 weeks training programme

\begin{tabular}{|c|c|c|}
\hline & Training group & Control group \\
\hline Age yrs & $51 \pm 10$ & $46 \pm 11$ \\
\hline BMI & $26 \pm 4$ & $26 \pm 4$ \\
\hline FEV1 L & $2.29 \pm 0.88$ & $2.38 \pm 0.86$ \\
\hline$\%$ pred & $76 \pm 23$ & $79 \pm 23$ \\
\hline RV L & $2.22 \pm 0.91$ & $2.41 \pm 0.88$ \\
\hline$\%$ pred & $113 \pm 48$ & $125 \pm 41$ \\
\hline$P a, O_{2} \mathrm{kPa}$ & $12.8 \pm 1.2$ & $13.8 \pm 6.0$ \\
\hline$V^{\prime} \mathrm{O}_{2} \cdot \mathrm{kg}^{-1} \mathrm{~mL} \cdot \mathrm{min}^{-1} \cdot \mathrm{kg}^{-1}$ & $15.5 \pm 7.2$ & $19.1 \pm 6.1$ \\
\hline HR, max \%pred & $81 \pm 12$ & $79 \pm 10$ \\
\hline$V^{\prime} \mathrm{E}$ max $\mathrm{L} \cdot \mathrm{min}^{-1}$ & $45.8 \pm 15.8$ & $44.8 \pm 16.7$ \\
\hline Borg,max & $3.5 \pm 1.9$ & $2.4 \pm 1.7$ \\
\hline
\end{tabular}

Data are presented as mean $\pm \mathrm{SD}$. Comparison by Student's t-test showed no significant differences. BMI: body mass index; FEV1: forced expiratory volume in one second; $\mathrm{RV}$ : residual volume; $\mathrm{Pa}_{\mathrm{a}} \mathrm{O}_{2}$ : arterial oxygen tension; $V^{\prime} \mathrm{O}_{2} \cdot \mathrm{kg}^{-1}$ : oxygen consumption as a proportion of body weight; HR,max: maximum cardiac frequency (heart rate) as a percentage of the predicted maximum heart rate; $V^{\prime} \mathrm{E}$,max: maximum minute ventilation; Borg,max: Borg score for breathlessness attained at peak exercise.
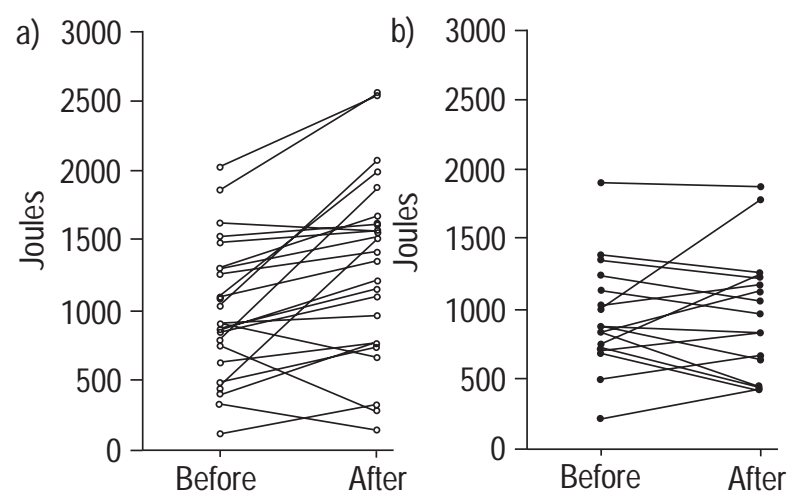

Training group

Control group

Fig. 1. - A comparison of isokinetic lower body muscle strength (i.e. lower limb concentric contraction (repeated contractions sustained for $60 \mathrm{~s})$ LC (SUS)) in a) the training and b) the control groups, before and after the 12 week programme. The mean difference in isokinetic muscle strength for the training group was 320 (95\% confidence interval (CI) $148-491)$ joules versus 32 (95\% CI -126-189) joules for the control group $(\mathrm{p}<0.02$, by Student's t-test).

$(p<0.001))$ and in one (Latissimus) of the three upper body exercises.

The training group demonstrated significant improvements in the sustained test $(60 \mathrm{~s})$ of isokinetic muscle work in both upper and lower limbs (the latter is given in fig. 1). There were no significant differences in the maximum contraction tests. A reanalysis of the factors influencing isokinetic muscle function in the "trained" COPD patients and the healthy sedentary subjects shows that after training "COPD" is no longer a significant variable:

$$
\begin{array}{r}
\mathrm{LC}(\mathrm{SUS})=-2844+11.2 \mathrm{Wt}-11.8 \mathrm{Age}+23 \mathrm{Ht} \\
\left(\mathrm{r}^{2}=0.48, \text { SEE } 81\right)
\end{array}
$$

Endurance work (joules) performed on the treadmill by the training group improved after the study period. The control group also increased their endurance work but a comparison of the mean changes between the two groups shows a significant difference, (control: mean difference $=$ 344 (95\% CI: 109-579) versus training:mean difference $=$ 4205 (95\% CI: 1,404-5,650), $\mathrm{p}<0.001)$.

The change in treadmill endurance correlated with the change in isokinetic sustained muscle strength (both expressed as a percentage change from baseline) for upper $\operatorname{limb}(r=0.54, p=0.001)$ and lower limb $(r=0.36, p=0.024)$ for the whole group and for the upper $\operatorname{limb}(\mathrm{r}=0.46, \mathrm{p}=$ 0.028 ) in the training group alone.

There was no significant difference in maximum exercise performance pre- versus poststudy period in either group with the exceptions of maximum tidal volume which showed an increase in the training group, and $V^{\prime} \mathrm{O}_{2}$, max which showed a fall in the control group (table 3 ). Further analysis was performed comparing the change in maximum exercise performance between the two groups. The mean changes in $V^{\prime} \mathrm{O}_{2}$, max, workload (W), minute ventilation $\left(V^{\prime} \mathrm{E}\right)$ and tidal volume were significantly different. This is as a result of slight increases in these variables in the training group and slight reductions in the control group following the study period.

An analysis of exercise performance at equivalent workload shows an increase in tidal volume (pre- $1.59 \pm 0.5$ 
Table 3. - Maximum exercise performance in the training and control groups after the 12 week training programme

\begin{tabular}{|c|c|c|c|c|}
\hline & \multicolumn{2}{|c|}{$\begin{array}{l}\text { Training } \\
\text { group }\end{array}$} & \multicolumn{2}{|c|}{$\begin{array}{l}\text { Control } \\
\text { group }\end{array}$} \\
\hline & Pre & Post & Pre & Post \\
\hline $\begin{array}{l}V^{\prime} \mathrm{O}_{2}, \max \\
\mathrm{mL} \cdot \mathrm{min}^{-1} \cdot \mathrm{kg}^{-1}\end{array}$ & $15.5 \pm 7.2$ & $16.6 \pm 8.4$ & $19.1 \pm 6.1$ & $16.6 \pm 4.0^{* *}$ \\
\hline $\begin{array}{l}\mathrm{HR}, \max \\
\text { beats } \cdot \min ^{-1}\end{array}$ & $133 \pm 20$ & $137 \pm 25$ & $133 \pm 21$ & $129 \pm 21$ \\
\hline $\begin{array}{l}V^{\prime} \mathrm{E}, \max \\
\mathrm{L} \cdot \min ^{-1}\end{array}$ & $45.8 \pm 15.8$ & $50.4 \pm 19.1$ & $44.8 \pm 16.7$ & $40.4 \pm 14.3$ \\
\hline$V_{\mathrm{T}, \max } \mathrm{L}$ & $1.71 \pm 0.50$ & $1.91 \pm 0.68^{*}$ & $1.69 \pm 0.45$ & $1.55 \pm 0.47$ \\
\hline $\begin{array}{l}\text { Resp. rate } \\
\text { breaths } \cdot \min ^{-1}\end{array}$ & $28 \pm 7$ & $27 \pm 60$ & $28 \pm 4$ & $28 \pm 4$ \\
\hline
\end{tabular}

Data are presented as mean $\pm \mathrm{SD}$. Comparison is by paired t-test, $*: \mathrm{p}=0.022, * *: \mathrm{p}=0.01 . V^{\prime} \mathrm{O}_{2}$, max: maximal oxygen consumption; HR,max: maximum cardiac frequency (heart rate); $V^{\prime} E$,max: maximal tidal volume; Resp.: respiration.

versus post-training $1.78 \pm 0.6, \mathrm{p}<0.05)$ in the training group. No other differences were seen in either group including Borg scores for breathlessness.

Following the study period there was no significant change in any aspect of lung function including arterial blood gases in either group.

There was a reduction in the body mass index (BMI) of $-0.61 \pm 1.1$ in the training group and an increase in the control group of $0.54 \pm 1.4, \mathrm{p}<0.005$.

\section{Discussion}

This study used two methods of assessing skeletal muscle function. Isotonic tests (where the muscle contracts and lengthens under a constant load) were used pre and post training to measure change in task-specific performance of the various Multigym exercises which constituted the training programme. Isokinetic tests (where the muscle contracts and lengthens at a constant velocity) were used to give a more comprehensive assessment of training, indicating changes in the main muscle groups trained, across the full range of normal movement (ROM). The presence of an accommodating resistance allows safe measurement of torque, work and power at constant speed throughout the complete ROM thus giving a full description of the functioning muscle. Isokinetics has an expanding range of contemporary applications in health-related and sportsrelated fitness and is likely to be increasingly used for outcome measurement following rehabilitation. The results for these two different functional measures used in this study are in broad agreement and are therefore taken as a whole when discussing the effects of training in part two of the study.

Part one of the study reveals that patients with mild COPD show a significant reduction in skeletal muscle endurance and strength compared with healthy but sedentary subjects. While upper limb maximal strength was reduced, upper limb "sustained" performance was not. This could be due to habitual recruitment of upper limb muscles in support of ventilation, a continuous, submaximal activity associated with improved endurance capability [11, 12]. SANCHEZ et al. [13] showed a significantly greater oxidative enzyme activity of the intercostal muscles of patients with COPD compared with healthy subjects and hypothesized that "COPD has an endurance training effect on respiratory muscles". It should however, be noted that in part two of the current study, the upper limb training programme did improve upper limb endurance, i.e. upper limb concentric contraction (UC) (SUS), indicating that these muscle groups are not already maximally trained. Since the lower limb muscles are independent of any direct pulmonary mechanical effects the abnormalities found are secondary effects on the exercising muscle. These abnormal results were found in relatively young patients with mild COPD at a stage of the illness when complications known to impair skeletal muscle function such as chronic hypoxaemia $[14,15]$, nutritional deficit [16, 17] and ageing [18] were not significant contributors. The results of blood gas analysis and oximetry both at rest and on exercise, plus BMI measures confirmed this. The potential contributions of drug therapy and cigarette smoking to skeletal muscle dysfunction have been mentioned recently by OELBERG et al. [19]. These factors would not explain the current results. There is no evidence that $\beta_{2}$-agonists in inhaled form, routine therapy in the COPD patients, have an adverse systemic effect on skeletal muscle function. None of the patients were taking theophyllines immediately prior to or during the study, nor were oral systemic steroids, which can cause myopathy [20], taken except as short courses for acute exacerbations in 3 patients. It is also unlikely that intracellular deoxyribonucleic acid (DNA) damage through smoking would explain the findings, even though the substantial majority of the patients were exsmokers, since the post-training study data would be unlikely to have shown such significant improvements in performance. Other studies, which have considered skeletal muscle abnormalities in COPD patients from various viewpoints including altered oxidative capacity $[16,6,4]$ enzyme activity [21, 5], muscle metabolites [16, 17, 4], metabolic performance [22] and morphology (fibre types) [4, 23] have all involved patients with severe disease and/or respiratory failure where hypoxia, malnutrition and administration of systemic steroids may act as comechanisms contributing to muscle dysfunction. For example, SERRES et al. [3] showed a significant reduction in quadriceps strength and endurance in 17 patients with severe COPD as compared with 8 control subjects, and also noted a relationship between the levels of dysfunction, FEV1 and hypoxia. In these circumstances it is difficult to identify an independent contribution of inactivity deconditioning. However, the partial improvements in skeletal muscle performance reported following training in patients with severe disease [24] provides circumstantial evidence for deconditioning as at least a comechanism and the present study data confirm this. Evidence of impaired skeletal muscle function following detraining is well established [25].

In part two of the study, skeletal muscle training produced a highly significant improvement in exercise endurance on treadmill walking, without central cardiorespiratory changes, and correlating with improved skeletal muscle function measures. The magnitude of improvement compares favourably with the outcome of rehabilitation programmes which have used whole body training over similar periods of time [26] and also reinforces the findings of a key study by SIMPSON et al. [27] who 
demonstrated improved exercise tolerance after weight training in COPD patients. The use of isokinetic measurements and normative data in the current study also allowed the accurate estimation of the extent of deficit in muscle function prior to intervention, while multiple regression analysis allowed the elimination of the confounding effects of age, sex, height and weight in comparing COPD patients with normal subjects. (In contrast to SiMPSON et al. [27] who did not include normal data and had a preponderance of females in the control group.)

The use of weight training as therapy to improve exercise tolerance appears to be more effective than pharmacological intervention described in two recent studies [28, 29] which used recombinant growth factor. This produced an increase in skeletal muscle mass and peak strength but failed to produce any increase in endurance work or exercise tolerance, both of which were recognized by the authors to be important target outcomes. In one study [29] there was actually a reduction in endurance as measured by a 6 min walk test and despite an increase in lean body mass there was no change in handgrip strength or exercise tolerance as measured by peak oxygen consumption and walking distance. Perhaps there could be practical benefit to be gained from the use of a combined approach to improve muscle strength via pharmacological intervention and endurance through weight training since loss of muscle strength in the elderly is a cause of balance problems and falls at home [30] and endurance is of course intrinsic to completion of many daily tasks.

In summary; 1) it has been shown that skeletal muscle dysfunction simple deconditioning occurs in mild chronic obstructive pulmonary disease and is likely to be due to other confounding factors such as hypoxia or malnutrition were absent; and 2) the programme of exercises offers an effective form of endurance training of the skeletal muscle groups involved in normal daily activities in order to correct this deconditioning and improve whole body exercise tolerance. Further studies will determine the benefits of rehabilitation using weight training in patient groups with more severe disease and additional complicating factors.

Acknowledgements. The authors would like to acknowledge the patience and support of I McKay in the preparation of this manuscript.

\section{References}

1. Gosselink R, Troosters T, Decramer M. Peripheral muscle weakness contributes to exercise limitation in COPD. $A m$ J Respir Crit Care Med 1996; 153: 976-980.

2. Hamilton AL, Killian KJ, Summers E, Jones NL. Muscle strength, symptom intensity, and exercise capacity in patients with cardiorespiratory disorders. Am J Respir Crit Care Med 1995; 152: 2021-2031.

3. Serres I, Gautier V, Varray A, Prefaut C. Impaired skeletal muscle endurance related to physical inactivity and altered lung function in COPD patients. Chest 1998; 113: 900-905.

4. Jakobsson P, Jorfeldt L, Brundin A. Skeletal muscle metabolites and fibre types in patients with advanced chronic obstructive pulmonary disease (COPD), with and without chronic respiratory failure. Eur Respir J 1990; 3: 192196.

5. Maltais F, Simard AA, Simard C, Jobin J, Desgagnes P, Leblanc P. Oxidative capacity of the skeletal muscle and lactic acid kinetics during exercise in normal subjects and in patients with COPD. Am J Respir Crit Care Med 1996; 153: 288-293.

6. Wuyam B, Payen JF, Levy P, et al. Metabolism and aerobic capacity in chronic respiratory failure related to chronic obstructive pulmonary disease. Eur Respir $J$ 1992; 5: 157-162.

7. Snider GL. Defining Chronic Obstructive Pulmonary Disease. In: Calverley P, Pride P, eds. Chronic Obstructive Pulmonary Disease. London, Chapman \& Hall, 1995; pp. 1-8.

8. Lowther MP, Mutrie N. Reliability and concurrent validity of the Scottish Physical Activity Questionnaire. $\mathrm{Br} J$ Sports Med 1996; 30: 368.

9. Berger R. Effect of varied weight training programmes on strength. Research Quarterly 1961; 33: 168-181.

10. Clark CJ, Cochrane L, Mackay E. Low intensity peripheral muscle conditioning improves exercise tolerance and breathlessness in COPD. Eur Respir J 1996; 9: 2590-2596.

11. Ries AL, Ellis B, Hawkins RW. Upper extremity exercise training in chronic obstructive pulmonary disease. Chest 1988; 93: 688-692.

12. Lake FR, Henderson K, Briffa T, Openshaw J, Musk AW. Upper-limb and lower-limb exercise training in patients with chronic airflow obstruction. Chest 1990; 97: 10771082.

13. Sanchez J, Brunet A, Medrano G, Debesse B, Derenne J. Metabolic enzyme activities in the intercostal and serratus muscles and in the latissimus dorsi of middle-aged normal men and patients with moderate obstructive pulmonary disease. Eur Respir J 1988; 1: 376-383.

14. Jakobsson P, Jorfeldt L. Long-term oxygen therapy may improve skeletal muscle metabolism in advanced chronic obstructive pulmonary disease patients with chronic hypoxaemia. Respir Med 1995; 89: 471-476.

15. Mannix ET, Boska MD, Galasetti P, Burton G, Manfredi F, Farber MO. Modulation of ATP production by oxygen in obstructive lung disease as assessed by 31P-MRS. $J$ Appl Physiol 1995; 78: 2218-2227.

16. Tada H, Kato H, Misawa $\mathrm{T}$, et al. P-Nuclear magnetic resonance evidence of abnormal skeletal muscle metabolism in patients with chronic lung disease and congestive heart failure. Eur Respir $J$ 1992; 5: 163-169.

17. Kutsuzawa T, Shioya K, Durita D, Haida M, Ohta Y, Tamabayashi H. P-NMR study of skeletal muscle metabolism in patients with chronic respiratory impairment. Am Rev Respir Dis 1992; 146: 1019-1024.

18. Harridge SDR, Young A. Skeletal muscle. In: Pathy MSJ, ed. Principles and Practice of Geriatric Medicine. 3rd Edn. London, John Wiley \& Sons Ltd., 1997; pp. 1-9.

19. Oelberg DA, Medoff BD, Markowitz DH, Pappagianopoulos PP, Ginns LC, Systrom DM. Systemic oxygen extraction during incremental exercise in patients with severe chronic obstructive pulmonary disease. Eur J Appl Physiol 1998; 78: 201-207.

20. Decramer M, De Bock V, Dom R. Functional and histologic picture of steroid-induced myopathy in chronic obstructive pulmonary disease. Am J Respir Crit Care Med 1996; 153: 1958-1964.

21. Jakobsson P, Jorfeldt L, Henriksson J. Metabolic enzyme activity in the quadriceps femoris muscle in patients with severe chronic obstructive pulmonary disease. Am J Respir Crit Care Med 1995; 151: 374-377.

22. Sue YK, Wasserman K, Morricca RB, Casaburi R. Metabolic acidosis during exercise in patients with chronic obstructive pulmonary disease: use of the V. Slope method for anaerobic threshold determination. Chest 1988; 94 : 931-938. 
23. Satta A, Migliori GB, Spanevolla A, et al. Fibre types in skeletal muscles of chronic obstructive pulmonary disease patients related to respiratory function and exercise tolerance. Eur Respir J 1997; 10: 2853-2860.

24. Maltais F, Leblanc P, Simard C, et al. Skeletal muscle adaptation to endurance training in patients with chronic obstructive pulmonary disease. Am J Respir Crit Care Med 1996; 154: 442-447.

25. MacDougall JD, Ward GR, Salen DG, Sutton JR. Biochemical adaptation of human skeletal muscle to heavy resistance training and immobilization. J Appl Physiol 1977; 43: 700-703.

26. Donner C, Muir JF. ERS Task Force position paper. Selection criteria and programmes for pulmonary rehabilitation in COPD patients. Eur Respir J 1997; 10: 744-757.

27. Simpson K, Killian K, McCartney N, Stubbing DG, Jones
NI. Randomised controlled trial of weightlifting exercise in patients with chronic airflow limitation. Thorax 1992; 47: 70-75.

28. Casaburi R, Carruthers E, Tosolini J, Phillips J, Bhasin S. Randomized placebo controlled trial of growth hormone in severe COPD patients undergoing endurance exercise training. Am J Respir Crit Care Med 1998; 158: A498.

29. Burdet L, de Muralt B, Schutz Y, Pichard C, Fitting JW. Administration of growth hormone to underweight patients with chronic obstructive pulmonary disease. A prospective, randomized, controlled study. Am J Respir Crit Care Med 1997; 156: 1800-1806.

30. Bastow MD, Rawlings J, Allison SP. Undernutrition, hypothermia and injury in elderly women with fractured femur; an injury response to altered metabolism? Lancet 1983; 1: 143-146. 